\title{
Genetic approaches to understanding human obesity
}

\author{
Shwetha Ramachandrappa and I. Sadaf Farooqi
}

University of Cambridge Metabolic Research Laboratories, Institute of Metabolic Science, Addenbrooke's Hospital, Cambridge, United Kingdom.

\begin{abstract}
Obesity and its associated comorbidities represent one of the biggest public health challenges facing the world today. The heritability of body weight is high, and genetic variation plays a major role in determining the interindividual differences in susceptibility or resistance to the obesogenic environment. Here we discuss how genetic studies in humans have contributed to our understanding of the central pathways that govern energy homeostasis. We discuss how the arrival of technological advances such as next-generation sequencing will result in a major acceleration in the pace of gene discovery. The study of patients harboring these genetic variants has informed our understanding of the molecular and physiological pathways involved in energy homeostasis. We anticipate that future studies will provide the framework for the development of a more rational targeted approach to the prevention and treatment of genetically susceptible individuals.
\end{abstract}

\section{Introduction}

The rising prevalence of obesity and associated comorbidities such as type 2 diabetes, cardiovascular disease, and certain cancers represents a major threat to public health worldwide (1). On a global level, changes in environmental factors undoubtedly drive the rise in the prevalence of obesity. However, one remarkable feature of the "obesity epidemic" is the persistence of considerable individual variation in body weight within a population that shares the same environment (2).

There is strong evidence that within a population the variance in BMI (weight in $\mathrm{kg} /$ height in meters squared) is largely genetically determined (3), with heritability estimates ranging between $40 \%$ and $70 \%$ (4). In a Swedish study of twins reared apart, within-pair correlations for BMI were 0.70 for male and 0.66 for female monozygotic twins $(5,6)$. Recent studies in twins born after the recent increase in the prevalence of obesity have estimated the heritability of BMI at 77\% (7). Further evidence comes from studies of adopted children, whose weight correlates better with that of their biological parents than with that of their adoptive parents with whom they share the childhood environment (8). Overfeeding studies have shown that the weight gain in response to positive energy balance differs across sets of identical twins but is similar between members of a twin pair $(9,10)$.

Given the estimated heritability of BMI, genetic approaches can be a useful tool with which to dissect the mechanisms involved in weight regulation and understand the susceptibility to obesity. To date, a number of contrasting experimental approaches have been used to identify human obesity-associated genes, including linkage studies, association studies, and candidate gene studies (ref. 3 and Table 1).

\section{Candidate gene studies}

Candidate gene studies based on the molecules known to cause severe obesity in experimental animals have shown that these genes also contribute to childhood onset human obesity. The foundation for this work was laid by elegant physiological studies showing that the regulation of body weight is a homeostatic process (11), which has been demonstrated by chemical and elec-

Conflict of interest: The authors have declared that no conflict of interest exists. Citation for this article: JClin Invest. 2011;121(6):2080-2086. doi:10.1172/JCI46044. trolytic lesioning studies to be critically regulated at the level of the hypothalamus $(12,13)$. Parabiosis experiments in inbred strains of mice with severe obesity, such as $o b / o b$ and $d b / d b$, suggested the existence of a circulating factor that regulates weight (14). The identification of this hormone, leptin, through positional cloning of the $o b$ gene and the finding that this was mutated in severely obese $o b / o b$ mice (15) paved the way for the molecular and physiological circuits controlling energy homeostasis to be dissected. Leptin is a $16-\mathrm{kDa}$ hormone whose circulating levels correlate closely with fat mass $(16,17)$. Prolonged fasting results in a fall in leptin levels, which triggers a series of changes in energy intake, energy expenditure, and neuroendocrine function in order to maintain energy homeostasis (18). Many of the physiological effects of leptin are mediated through the central nervous system, particularly the hypothalamus, which is the site of the highest mRNA expression of the long isoform of the leptin receptor $(19,20)$. Studies by many groups have demonstrated that leptin stimulates the expression of pro-opiomelanocortin (POMC) in primary neurons located in the arcuate nucleus of the hypothalamus. POMC is extensively posttranslationally modified to generate the melanocortin peptides, which activate the melanocortin receptors to modulate diverse functions in the central nervous system, the adrenal gland, and skin $(21,22)$. The melanocortins are agonists at melanocortin receptors and suppress food intake. In addition, leptin inhibits orexigenic pathways, mediated by neurons expressing the melanocortin antagonist Agouti-related protein and neuropeptide Y (NPY); NPY can suppress the expression of POMC. These two sets of primary leptin-responsive neurons project to second-order neurons expressing the melanocortin 4 receptor (MC4R). Targeted genetic disruption of MC4R in mice leads to increased food intake and increased lean mass and linear growth (23). These hypothalamic pathways interact with other brain centers to coordinate appetite and modulate efferent signals to the periphery, regulating intermediary metabolism and energy expenditure.

We and others have demonstrated that human obesity can result from a multiplicity of defects in the leptin/melanocortin pathway. In this review we will focus on the physiological effects of genetic disruption of these and other obesity-associated genes. 


\section{Table 1}

\section{Genetic obesity syndromes}

$\begin{array}{lccc}\text { Obesity syndrome } & \text { Gene name } & \text { Main distinguishing features } & \text { References } \\ \text { LEP deficiency } & \text { LEP } & \text { Hypogonadism, frequent infections, undetectable serum leptin } & 24-26 \\ \text { LEPR deficiency } & \text { LEPR } & \text { Hypogonadism } & 29,30 \\ \text { POMC deficiency } & \text { HOMC } & \text { Hypopigmentation, isolated ACTH deficiency } & 46,47 \\ \text { PCSK1/3 deficiency } & \text { PCSK1 } & \text { Postprandial hypoglycemia, hypogonadism, elevated plasma proinsulin and 32-33 split proinsulin } & 52,53 \\ \text { MC4R deficiency } & \text { MC4R } & \text { Accelerated growth, increased final height } & 55,57-59 \\ \text { BDNF deficiency } & \text { BDNF } & \text { Developmental delay, hyperactivity, impaired memory, impaired pain sensation } & 71,72 \\ \text { TrkB deficiency } & \text { NTRK2 } & \text { Developmental delay, hyperactivity, impaired memory, impaired pain sensation } & 70 \\ \text { SIM1 deficiency } & \text { SIM1 } & \text { Spectrum of developmental delay } & 74 \\ \text { BBS } & \text { BBS1-16 } & \text { Polydactyly, retinal dystrophy, hypogonadism, renal abnormalities, developmental delay } & 80,81 \\ \text { Alström syndrome } & \text { ALMS1 } & \text { Photophobia, nystagmus, visual impairment, deafness, severe insulin resistance } & 81 \\ \text { AH0 } & \text { GNAS1 } & \text { Short stature, skeletal defects, hormone resistance } & 89 \\ & & & \end{array}$

\section{Leptin and leptin receptor mutations}

Homozygous frameshift, nonsense, and missense mutations of the leptin gene (LEP) have been identified, which result in an inability to produce leptin; patients with such $L E P$ mutations are severely obese from a young age, and their LEP levels are below the lower limit of detection (24-26). Congenital leptin deficiency can be successfully treated with daily injections of recombinant human leptin, correcting all the metabolic abnormalities seen in these patients $(27,28)$. Up to $3 \%$ of patients with severe obesity have been found to harbor loss-of-function mutations in the LEP receptor $(L E P R)$ (29). The clinical phenotypes associated with congenital deficiency of either leptin or its receptor are very similar $(29,30)$ and illustrate that, in humans, leptin is a key regulator of energy intake and eating behavior, energy expenditure, neuroendocrine function, and immunity.

Regulation of energy intake. Leptin- and leptin receptor-deficient subjects are born of normal birth weight but exhibit rapid weight gain in the first few months of life, which results in severe obesity. The key features are an intense drive to eat (hyperphagia), with aggressive behavior when food is denied, as well as impaired satiety, with food-seeking behavior initiating soon after the end of a meal (28). The major effect of leptin administration is on food intake, with normalization of hyperphagia and enhanced satiety $(28,31)$. Leptin is also involved in mediating food reward. We used functional MRI scans to measure changes in blood flow, which reflect changes in neuronal activation, in response to the visual presentation of pictures of food versus pictures of non-food items (32). In the leptin-deficient state, images of food (compared to non-food images) were associated with a marked increase in neuronal activation in the ventral striatum, an area associated with pleasure and reward. This response was normalized by seven days of leptin treatment (32). Our findings are consistent with the view that activation in the ventral striatum does not directly encode the "liking" but rather the motivational salience, or "wanting", of food. Recent studies by Rosenbaum, Leibel, and colleagues in obese volunteers in an energy-restricted, partially leptin-deficient state, are consistent with the view that these responses are part of the physiological response to reduced body weight (33). In rodents, leptin receptors are expressed in the mesolimbic system, which is thought to mediate the rewarding properties of food and drugs (34). Leptin administration decreases the firing threshold of dopaminergic neurons within this system, and knockdown of leptin receptors on these neurons has been shown to increase food intake (35).
Regulation of energy expenditure and fat oxidation. In leptin-deficient children and adults, basal metabolic rate, total energy expenditure, and free-living energy expenditure are appropriate for body composition of these patients $(28,31)$. We have shown that leptin administration does not result in a change in energy expenditure; however, as weight loss by other means is associated with a decrease in basal metabolic rate, the absence of an effect is notable (28). Ravussin and colleagues confirmed this in elegant studies of 24-hour energy expenditure and fat oxidation in three leptin-deficient obese adults before and after weight loss and three obese controls pair-matched for gender, age, and BMI, in whom weight loss was induced by a 10- to 21week low-calorie diet (36). Before weight loss, leptin-deficient and matched controls had similar energy expenditures. However, after weight loss, controls had energy expenditures lower than expected for their new weight and body composition. This is a well-known phenomenon, often called the metabolic adaptation to weight loss, i.e., a decrease in metabolic rate beyond that expected on the basis of the decrease in fat-free mass and fat mass. Further studies in obese volunteers following energy restriction support the conclusion that leptin does affect energy expenditure in humans (37), as the fall in energy expenditure seen after $10 \%$ weight loss is attenuated by the administration of leptin.

Body composition measurements show that leptin deficiency is characterized by the preferential deposition of fat mass (compared with lean mass), and weight loss leads to a preferential loss of fat mass (28). In rodents, leptin stimulates fatty acid oxidation in skeletal muscle via the stimulation of AMP kinase activity (38). In leptin-deficient humans, impaired fat oxidation has been demonstrated by chamber calorimetry (36). How might effects on energy expenditure and fat oxidation be mediated in humans? Ozata and colleagues have reported abnormalities of sympathetic nerve function in leptin-deficient adults consistent with defects in the efferent sympathetic limb of thermogenesis (39). Also relevant to the regulation of human energy expenditure are changes in thyroid function seen in patients with leptin deficiency (25). Evidence from rodents suggests that leptin is necessary for the normal biosynthesis and secretion of thyrotropin-releasing hormone and that complete leptin deficiency is associated with a moderate degree of hypothalamic hypothyroidism characterized by low free thyroxine and high serum thyroid-stimulating hormone, which is bioinactive. Similar effects are seen in weight-reduced humans and are reversed by leptin administration (40). 
Leptin as a metabolic gate for the onset of puberty. Leptin deficiency is associated with hypogonadotropic hypogonadism and a failure of normal pubertal development (26). The administration of leptin permits progression of appropriately timed pubertal development, suggesting that leptin is a permissive factor for the development of puberty in humans $(28,31)$. However, there is some evidence for the delayed but spontaneous onset of menses in some leptin receptor-deficient adults (29); it is plausible that in these patients, the excess adipose tissue mass leads to the production of sufficient estrogen (due to the action of aromatase), to result in uterine development and irregular menses in the absence of fully developed secondary sexual characteristics. Leptin may exert these effects on the reproductive system through a number of molecules including kisspeptin, which signals through GPR54, to modify the release of gonadotrophin-releasing hormone (41), and through specific neural pathways involving the ventral premamillary nucleus (42).

Leptin as a mediator of the nutritional regulation of immune function. Leptin stimulates inflammatory responses, T lymphocyte proliferation, and Th1 cytokine production during fasting in normal mice and in $o b / o b$ mice, indicating that it is an important link between nutrition and the immune system. Recent studies have shown that leptin is also involved in mediating the systemic response to sepsis (43) and in parasitic diseases (44). Patients with leptin deficiency have an increased frequency of infections and marked abnormalities of $\mathrm{T}$ cell number and function in vitro, which are normalized with leptin treatment $(28,31)$. The multiple effects of leptin on innate and adaptive immunity suggest that immunomodulation by leptin may have therapeutic potential in a range of human diseases (45).

\section{Mutations that disrupt melanocortin signaling}

Leptin signaling modulates energy balance through a combination of melanocortin-dependent and -independent pathways. In humans, null mutations in POMC lead to hyperphagia, earlyonset obesity, isolated adrenocorticotrophin (ACTH) deficiency, and hypopigmentation of skin and hair (46-48). Heterozygous carriers of null mutations have a significantly higher risk of being obese or overweight (48). This is particularly relevant, as we and others have described a number of heterozygous point mutations in POMC and loss-of-function mutations in $\alpha$ - and $\beta$-melanocyte-stimulating hormone ( $\alpha$ - and $\beta$-MSH), which significantly increase obesity risk but are not invariably associated with obesity $(49,50)$. These studies support a previously unrecognized role for $\beta$-MSH in the control of human energy homeostasis. Through the detailed functional characterization of obesity-associated mutations, we were able to show a role for the $\mathrm{N}$ terminus of POMC in the sorting and secretion of POMC-derived peptides (51).

Prohormone convertase 1 (PCSK1) is an enzyme involved in the cleavage of POMC into ACTH, which is then further cleaved to make $\alpha$-MSH by carboxypeptidase E. Humans lacking PCSK1 are severely obese and have glucocorticoid deficiency, hypogonadotropic hypogonadism, and postprandial hypoglycemia, which occurs as a result of impaired processing of proinsulin to insulin $(52,53)$. Elevated plasma levels of proinsulin and 32-33 split proinsulin in the context of low levels of mature insulin provide the basis for a diagnostic test for this disorder. A prominent clinical feature of affected individuals is severe absorptive dysfunction of the small intestine in neonatal life $(53,54)$, which is likely to be attributable to impaired processing of propeptides within the enteroendocrine cells and nerves that express PCSK1 throughout the gut (53).
We and others have reported that mutations in MC4R are found in 5\%-6\% of patients with severe early-onset obesity (55) and at a frequency of approximately $1 / 1,000$ in the general UK population (56), making this one of the most common human monogenic diseases $(57,58)$. Functionally significant MC4R mutations are inherited in a codominant manner, with variable penetrance and expression in heterozygous carriers $(55,59)$. Most naturally occurring disease-causing MC4R mutations disrupt normal expression and trafficking of the receptor to the cell surface $(58,60)$. As a result of this growing body of information, assessment of the sequence of the MC4R is increasingly seen as a necessary part of the clinical evaluation of the severely obese child (61). The mechanism of GPCR dysfunction has potential interest, as we have shown that pharmacological chaperones can increase the cell surface expression and signalling of mutant GPCRs (62).

Regulation of energy intake, energy expenditure, and fat oxidation. We have previously characterized human MC4R deficiency and reported hyperphagia, increased lean mass, and increased linear growth and demonstrated a genotype-phenotype correlation with the degree of receptor dysfunction in vitro predicting all aspects of the phenotype, including ad libitum energy intake (55). These features are also seen in patients with heterozygous mutations that affect the production of $\alpha$ - and $\beta-\mathrm{MSH}$ (49). Further studies established that MC4R plays a role in fat oxidation and nutrient partitioning. These effects are also seen in rodents and appear to be mainly mediated by the sympathetic nervous system. Retrograde viral tracing of the origins of sympathetic outflow to white adipose tissue (WAT) depots has identified several hypothalamic areas expressing MC4R, in particular the $\mathrm{PVN}$, as sites of presympathetic neurons that project to WAT (63). Furthermore, intracerebroventricular administration of melanocortin agonists has been shown to increase sympathetic nervous activity in WAT and modulate triacylglycerol metabolism to promote lipid mobilization (63). Central pharmacological MCR blockade leads to less weight gain in triple $(\beta 1 / \beta 2 / \beta 3)$ adrenergic knockout mice than in wild-type mice, suggesting that reducing sympathetic tone to WAT, which directly promotes fat accumulation, may be an important mechanism by which MC4R deficiency leads to obesity (63).

Regulation of sympathetic tone and blood pressure. Acute central administration of $\alpha$-MSH increases mean arterial pressure and heart rate in rodents. Chronic pharmacologic blockade of MC3R and MC4R causes weight gain and a reduction in heart rate but no increase in arterial pressure. $M c 4 r$-null mice maintain normal blood pressure despite marked obesity and are unresponsive to the pressor effects of central $\alpha$-MSH administration (64). We have shown that both increases and decreases in central melanocortin signaling influence blood pressure in humans and that the effects are not explained by changes in circulating insulin levels or insulin sensitivity (65). MC4R-deficient patients with long-standing decreases in melanocortinergic tone have a lower prevalence of hypertension and lower systolic and diastolic blood pressures. These changes are associated with reduced sympathetic nervous system activity (65). Also, administration of a melanocortin receptor agonist in obese volunteers increases blood pressure (65). Thus, central melanocortin signalling appears to play an important role in the regulation of blood pressure and its coupling to changes in weight (66).

Regulation oflinear growth. Mutations in POMC and MC4R are associated with accelerated linear growth that is disproportionate to the degree of obesity. Hyperinsulinemia is seen in very young MC4Rdeficient children, persists throughout childhood, and is likely to be a major mediator of the increased linear growth (55). Whereas pulsatile growth hormone $(\mathrm{GH})$ secretion is suppressed in obese controls, 
GH levels were not completely suppressed in MC4R-deficient adults (67), suggesting that the suppression of pulsatile GH secretion in obesity is mediated by signaling through MC4R. GH secretion is under the reciprocal control of the hypothalamic hormones $\mathrm{GH}$ releasing hormone (GHRH), which determines the amplitude of the GH peak, and somatostatin, which determines the trough levels of GH by inhibiting GHRH release and GH secretion. Although there have been no studies of $\mathrm{GH}$ release in $M c 4 r$-knockout mice, the somatotroph axis has been studied in the agouti mouse, which overexpresses Agouti protein, a natural antagonist at Mc4r. Martin et al. showed that although Ghrb mRNA expression in the arcuate nucleus of obese agouti mice was unchanged, somatostatin peptide content and somatostatin mRNA levels in the periventricular nucleus were reduced to $50 \%$ of wild-type levels (68). The neural networks that mediate the coupling of these pathways need to be elucidated.

\section{Mutations in molecules downstream of MC4R}

Brain-derived neurotrophic factor (BDNF) is one of several nerve growth factors which activate signaling by the tyrosine kinase receptor tropomycin-related kinase $\mathrm{B}(\operatorname{TrkB})$. Infusion of $\mathrm{BDNF}$ reduces food intake in models of MC4R deficiency, suggesting that BDNF/ TrkB signaling may lie distal to MC4R signaling (69). Haploinsufficient mice and mice in which BDNF has been deleted postnatally are obese with hyperphagia and hyperactivity. We reported a child with severe obesity, impaired short-term memory, and developmental delay who had a de novo missense mutation impairing the function of $\operatorname{TrkB}(70)$. We have also identified a patient with a de novo chromosomal inversion, 46,XX,inv(11)(p13p15.3), which encompasses the BDNF locus and disrupts BDNF expression (71). Yanovski and colleagues showed that in patients with WAGR syndrome, a subset of deletions encompassing the BDNF locus were associated with early-onset obesity (72).

Another molecule thought to lie downstream of MC4R-expressing neurons is single minded 1 (SIM1), a transcription factor involved in the development of the paraventricular and supraoptic nuclei of the hypothalamus. A de novo balanced translocation between chromosomes 1p22.1 and 6q16.2, which disrupts SIM1 (73), and missense mutations in SIM1 cause severe obesity and a variable phenotype of developmental delay (74). Heterozygous Sim1-null mice are hyperphagic and obese and have increased linear growth (75); several lines of evidence suggest that SIM1 may lie downstream of MC4R signaling in the paraventricular nucleus $(76,77)$. The transcriptional targets of SIM1 are unknown, but one potential target is the neuropeptide oxytocin. Oxytocin mRNA levels are reduced in line with $\operatorname{Sim} 1$ gene dosage in mouse models of Sim1 deficiency. The hyperphagia of Sim1-haploinsufficient animals is ameliorated by oxytocin administration and accentuated by the administration of oxytocin receptor antagonists (78).

\section{Developmental obesity syndromes involving ciliary dysfunction}

Bardet-Biedl syndrome (BBS) is an autosomal recessive disease characterized by learning difficulties, polydactyly, retinal dystrophy, hypogonadism, renal abnormalities, and obesity. BBS is genetically heterogeneous, with mutations in more than 14 genes identified to date (79). Many of these genes appear to affect proteins localized to the basal body, a key element of the monocilium thought to be important for intercellular sensing in mammalian cells including neurons (80). Other disorders of ciliary function (e.g., Alström syndrome and Carpenter syndrome) can also lead to obesity (81).
Recent studies have suggested a connection between ciliary function and leptin signaling (82). Conditional postnatal knockout of proteins involved in intraflagellar transport in mice results in hyperphagia and obesity (83). This phenotype is recapitulated when the loss of cilia is limited to neurons and when it is specifically targeted to POMC neurons (83). The role of cilia in key neuronal populations involved in energy homeostasis will be the subject of intense future research.

\section{Imprinted genetic syndromes}

Prader-Willi syndrome (PWS) is a clinical syndrome of hypotonia, mental retardation, short stature, hypogonadism, hyperphagia, and obesity caused by lack of expression of genes on chromosome $15 q 11-13$, which are imprinted such that they are only expressed on the paternally inherited copy of the chromosome. These transcripts include SNURF-SNRPN and multiple small nucleolar RNAs (snoRNAs), in particular the HBII-85 snoRNAs $(84,85)$. Further investigation is required to determine how the loss of these noncoding sequences could lead to the range of phenotypes associated with PWS. High serum ghrelin concentrations $(86,87)$ and loss of oxytocin-producing neurons in the brains of patients (88) suggest these hormones and neuropeptides may be important in this disorder.

Albright hereditary osteodystrophy (AHO) is an autosomal dominant disorder resulting from germline mutations in GNAS1 that decrease expression or function of Gs $\alpha$ protein. Maternal transmission of GNAS1 mutations leads to AHO (characterized by short stature, obesity, skeletal defects, and impaired olfaction) plus resistance to several hormones (e.g., parathyroid hormone) that activate Gs in their target tissues; paternal transmission leads only to the AHO phenotype (89). Mice lacking maternally derived Gs $\alpha$ are obese, and similar to MC4R-deficient mice, they have reduced sympathetic tone but are not hyperphagic (90). Gs $\alpha$-independent signaling appears to mediate the effect of melanocortins on food intake, whereas Gs $\alpha$ dependent signaling mediates the effect of melanocortins on sympathetic tone and energy expenditure.

\section{Copy number variants}

Copy number variants (CNVs), which include gains (duplications or insertions), losses (deletions), and rearrangements, have been estimated to account for nearly $18 \%$ of the heritable variance in gene expression. We and others have identified several rare CNVs recurrent among severely obese patients and enriched relative to controls $(91,92)$. Deletion of a $220-\mathrm{kb}$ segment of $16 \mathrm{p} 11.2$ is associated with highly penetrant familial severe early-onset obesity and severe insulin resistance (91). This deletion includes a small number of genes, one of which is $S H 2 B 1$, known to be involved in leptin and insulin signaling (91). These patients gain weight in the first years of life, with hyperphagia and fasting plasma insulin levels that are disproportionately elevated compared to age- and obesity-matched controls. This phenotype resembles the severe obesity and insulin resistance seen in mice with targeted deletion of $\operatorname{Sh} 2 b 1$ (93).

\section{Common genetic variants associated with increased risk of obesity}

By genotyping on average 350,000-500,000 SNPs covering more than $75 \%$ of the genome, genome-wide association studies (GWASs) conducted in population-based cohorts assessed for body mass index or in case-control designs for obesity have led to 
the identification of several interesting genetic loci. These studies are based on the premise that the heritability of common diseases is made up of a large number of common disease-causing variants, which exceed a minor allele frequency (MAF) of 5\%. The first loci detected were variants in the FTO (fat mass and obesity associated) gene $(94,95)$ and variants approximately $200 \mathrm{~kb}$ downstream of MC4R (96). Altogether, more than 20 genetic loci relevant for body weight regulation have been identified by GWAS approaches (97).

It is important to recognize that GWASs identify associations between diseases and regions of the genome, not specific genes. Many of the signals identified map to noncoding regions of the genome, and the interpretation of signals relies heavily on the current annotation of the regions implicated. Genes within the region of interest are evaluated as potential candidates for causing the association, but the association may also conceivably arise due to long-range genetic interactions or other as yet poorly understood genetic phenomena. Not surprisingly, understanding the biological basis of these association signals is still at an early stage. The strongest association with BMI in individuals of mixed European descent has consistently been found with SNPs in the first intron of FTO. Homozygotes for the risk allele of the most common SNP in FTO are 3-4 kg heavier than those without the risk allele and have a 1.67-fold increased risk of obesity (94). Several human studies have demonstrated an association between SNPs in FTO and energy intake $(98,99)$ rather than energy expenditure. FTO is expressed in the hypothalamus, and its expression is nutritionally regulated $(100,101)$. Fto-null mice are small with increased energy expenditure (102) whereas mice overexpressing Fto are obese (103). FTO has been shown to be a dioxygenase with the ability to demethylate 3-methylthymine in DNA in vitro (100), but the relevance of this observation to its in vivo function remains to be seen.

\section{Finding the missing heritability in human obesity}

The common variants uncovered in GWASs are characterized by modest effect sizes (per-allele odds ratios between 1.2 and 1.5), and the proportion of variability explained by GWAS-identified loci to date remains relatively modest $(<10 \%)$. There is the possibility that the heritability of obesity-related phenotypes may have been overestimated, as the effects of the shared environment and, in the case of twins, the shared in utero environment, are difficult to separate from inherited influences. Nonetheless, several approaches are being used to explain the missing genetic heritability.

There is a growing consensus in the study of common complex diseases that the common disease-common variant hypothesis is not going to explain the missing heritability. In obesity, common variants influencing susceptibility to common obesity and more highly penetrant rare variants at the same loci, including CNVs, associated with severe early-onset forms of the disease have already been demonstrated (e.g., MC4R, SH2B1, BDNF) $(96,104,105)$. The state of the art technique for finding low-frequency/rare genetic variants relies on next-generation sequencing technologies to undertake whole exome sequencing, in which tens of thousands of coding variants are identified per individual (106). Not every variant will be identified due to variable depth of coverage, misalignment of reads, and the inherent complexity of repetitive regions of the genome. Those that are identified must be carefully refined to identify potentially pathogenic variants. Functional data, as well as predictions of the impact of variants on protein function, can also be incorporated into the filtering process. While statistical and computational methods are continually emerging to address these challenges, as with other hypothesis-free genetic approaches the technique is ultimately only as powerful as the genetic material being interrogated. Initial methodological approaches have tended toward sequencing related individuals (107), or sequencing individuals at opposing extremes of the phenotypic spectrum (108). To date, virtually all research into finding genes related to obesity has focused on the upper end of the body mass index distribution. Evolutionary models, animal models, and analogies with other disease areas all suggest that searching for genes influencing body weight may be profitably pursued by studying very thin, healthy individuals. Thinness appears to be a trait that is as stable and heritable as obesity (109). The successful application of this technology to well-characterized patient groups has the potential to transform gene discovery in human metabolic disease.

This technology has already been used for genetic diagnosis and to identify novel proteins disrupted in Mendelian disease (110), but its application in complex diseases such as obesity is likely to be even more challenging. Understanding the pathogenic potential of individual mutations in the context of variation at other loci that may act as modifiers will hinge on the development of physiologically relevant assays in cell or animal systems to tease apart the biological causality of variants.

Although it is difficult to distinguish between purely environmental effects and interactions between the environment and epigenetic factors, genome-wide measurement of epigenetic variation has recently been made possible using techniques such as DNA methylation-specific microarrays. In primates, exposure of mothers to a high-fat diet in pregnancy has major implications for the development of metabolic disease in the offspring (111). The implications of these findings for human obesity remain unclear at present, although in a recent study a number of variably methylated regions that differed among individuals but were stable over time were found to correlate with BMI (112).

Given the increasing availability of next-generation sequencing technologies, it is very likely that new genes, proteins, and mechanisms will emerge within the next 10 years. Translating basic discoveries into advances in clinical practice remains a key long-term challenge.

\section{Acknowledgments}

The Obesity Review Series is supported in part by unrestricted educational grants from Merck \& Co. and the Life Sciences Institute of the University of Michigan.

Address correspondence to: I. Sadaf Farooqi, University of Cambridge Metabolic Research Laboratories, Institute of Metabolic Science, Box 289, Addenbrooke's Hospital, Cambridge, CB2 0QQ, United Kingdom. Phone: 44.1223.762.634; Fax: 44.1223.762.657; E-mail: isf20@cam.ac.uk.

\footnotetext{
1. Friedman JM. Obesity in the new millennium Nature. 2000;404(6778):632-634.

2. Wardle J, Carnell S, Haworth CM, Plomin R. Evidence for a strong genetic influence on childhood adiposity despite the force of the obesogenic environment. Am J Clin Nutr. 2008;87(2):398-404.

3. Barsh GS, Farooqi IS, O'Rahilly S. Genetics of body-
}

weight regulation. Nature. 2000;404(6778):644-651.

4. Allison DB, Kaprio J, Korkeila M, Koskenvuo M, Neale MC, Hayakawa K. The heritability of body mass index among an international sample of monozygotic twins reared apart. Int J Obes Relat Metab Disord. 1996;20(6):501-506.

5. Stunkard AJ, Foch TT, Hrubec Z. A twin study of human obesity. JAMA. 1986;256(1):51-54.

6. Stunkard AJ, Harris JR, Pedersen NL, McClearn GE. The body-mass index of twins who have been reared apart [see comments]. $N$ Engl J Med. 1990;322(21):1483-1487.

7. Haworth CM, Plomin R, Carnell S, Wardle J. Childhood obesity: genetic and environmental overlap 
with normal-range BMI. Obesity (Silver Spring). 2008;16(7):1585-1590.

8. Sorensen TI, Price RA, Stunkard AJ, Schulsinger F. Genetics of obesity in adult adoptees and their biological siblings. BMJ. 1989;298(6666):87-90.

9. Bouchard C, et al. The response to long-term overfeeding in identical twins [see comments]. N Engl J Med. 1990;322(21):1477-1482.

10. Bouchard C, et al. Overfeeding in identical twins: 5-year postoverfeeding results. Metabolism. 1996; 45(8):1042-1050.

11. Kennedy GC. The role of depot fat in the hypothalamic control of food intake in the rat. Proc $R$ Soc Lond B Biol Sci. 1953;140(901)578-596.

12. Anand BK, Brobeck JR. Hypothalamic control of food intake in rats and cats. Yale J Biol Med. 1951;24(2):123-146.

13. Hervey GR. The effects of lesions in the hypothalamus in parabiotic rats. J Physiol London. 1959;145(2):336.

14. Coleman DL, Hummel KP. Effects of parabiosis of normal with genetically diabetic mice. Am J Physiol. 1969;217(5):1298-1304.

15. Zhang Y, Proenca R, Maffei M, Barone M, Leopold L, Friedman JM. Positional cloning of the mouse obese gene and its human homologue [published erratum appears in Nature 1995 Mar 30;374(6521):479] [see comments]. Nature. 1994;372(6505):425-432.

16. Maffei M, et al. Leptin levels in human and rodent: measurement of plasma leptin and ob RNA in obese and weight-reduced subjects. Nat Med. 1995;1(11):1155-1161.

17. Considine RV, et al. Serum immunoreactiveleptin concentrations in normal-weight and obese humans [see comments]. $N$ Engl J Med. 1996; 334(5):292-295.

18. Ahima RS, et al. Role of leptin in the neuroendocrine response to fasting. Nature. 1996 382(6588):250-252.

19. Chen $\mathrm{H}$, et al. Evidence that the diabetes gene encodes the leptin receptor: identification of a mutation in the leptin receptor gene in $\mathrm{db} / \mathrm{db}$ mice. Cell. 1996;84(3):491-495.

20. Elmquist JK, Bjorbaek C, Ahima RS, Flier JS, Saper CB. Distributions of leptin receptor $\mathrm{mRNA}$ isoforms in the rat brain. J Comp Neurol. 1998;395(4):535-547.

21. Cone RD. Anatomy and regulation of the central melanocortin system. Nat Neurosci. 2005;8(5):571-578.

22. Schwartz MW, Woods SC, Porte D Jr, Seeley RJ, Baskin DG. Central nervous system control of food intake. Nature. 2000;404(6778):661-671

23. Huszar D, et al. Targeted disruption of the melanocortin- 4 receptor results in obesity in mice. Cell. 1997;88(1):131-141.

24. Montague CT, et al. Congenital leptin deficiency is associated with severe early-onset obesity in humans. Nature. 1997;387(6636):903-908.

25. Gibson WT, et al. Congenital leptin deficiency due to homozygosity for the Delta133G mutation: report of another case and evaluation of response to four years of leptin therapy. J Clin Endocrinol Metab. 2004;89(10):4821-4826.

26. Strobel A, Issad T, Camoin L, Ozata M, Strosberg AD. A leptin missense mutation associated with hypogonadism and morbid obesity. Nat Genet. 1998;18(3):213-215.

27. Farooqi IS, et al. Effects of recombinant leptin therapy in a child with congenital leptin deficiency. NEngl J Med. 1999;341(12):879-884.

28. Farooqi IS, et al. Beneficial effects of leptin on obesity, $\mathrm{T}$ cell hyporesponsiveness, and neuroendocrine/ metabolic dysfunction of human congenital leptin deficiency. J Clin Invest. 2002;110(8):1093-1103.

29. Farooqi IS, et al. Clinical and molecular genetic spectrum of congenital deficiency of the leptin receptor. N Engl J Med. 2007;356(3):237-247.

30. Clement $\mathrm{K}$, et al. A mutation in the human leptin receptor gene causes obesity and pitu- itary dysfunction [see comments]. Nature. 1998; 392(6674):398-401.

31. Licinio J, et al. Phenotypic effects of leptin replacement on morbid obesity, diabetes mellitus, hypogonadism, and behavior in leptin-deficient adults. Proc Natl Acad Sci U S A. 2004;101(13):4531-4536.

32. Farooqi IS, Bullmore E, Keogh J, Gillard J, O'Rahilly S, Fletcher PC. Leptin regulates striatal regions and human eating behavior. Science. 2007;317(5843):1355.

33. Rosenbaum M, Sy M, Pavlovich K, Leibel RL, Hirsch $\mathrm{J}$. Leptin reverses weight loss-induced changes in regional neural activity responses to visual food stimuli. J Clin Invest. 2008;118(7):2583-2591.

34. Fulton $S$, et al. Leptin regulation of the mesoaccumbens dopamine pathway. Neuron. 2006; 51(6):811-822.

35 . Hommel JD, et al. Leptin receptor signaling in midbrain dopamine neurons regulates feeding. Neuron. 2006;51(6):801-810.

36. Galgani JE, Greenway FL, Caglayan S, Wong ML, Licinio J, Ravussin E. Leptin replacement prevents weight loss-induced metabolic adaptation in congenital leptin-deficient patients. J Clin Endocrinol Metab. 2010;95(2):851-855

37. Rosenbaum M, et al. Low-dose leptin reverses skeletal muscle, autonomic, and neuroendocrine adaptations to maintenance of reduced weight. J Clin Invest. 2005;115(12):3579-3586.

38. Minokoshi Y, et al. Leptin stimulates fatty-acid oxidation by activating AMP-activated protein kinase. Nature. 2002;415(6869):339-343.

39. Ozata M, Ozdemir IC, Licinio J. Human leptin deficiency caused by a missense mutation: multiple endocrine defects, decreased sympathetic tone, and immune system dysfunction indicate new targets for leptin action, greater central than peripheral resistance to the effects of leptin, and spontaneous correction of leptin-mediated defects. J Clin Endocrinol Metab. 1999;84(10):3686-3695.

40. Rosenbaum M, Murphy EM, Heymsfield SB, Matthews DE, Leibel RL. Low dose leptin administration reverses effects of sustained weight-reduction on energy expenditure and circulating concentrations of thyroid hormones. J Clin Endocrinol Metab. 2002;87(5):2391-2394

41. Chan YM, Broder-Fingert S, Seminara SB. Reproductive functions of kisspeptin and Gpr54 across the life cycle of mice and men. Peptides. 2009;30(1):42-48.

42. Donato J Jr, et al. Leptin's effect on puberty in mice is relayed by the ventral premammillary nucleus and does not require signaling in Kiss 1 neurons. J Clin Invest. 2011;121(1):355-368.

43. Tschop J, et al. CNS leptin action modulates immune response and survival in sepsis. J Neurosci. 2010;30(17):6036-6047.

44. Nagajyothi F, et al. Crucial role of the central leptin receptor in murine Trypanosoma cruzi (Brazil strain) infection. J Infect Dis. 2010;202(7):1104-1113.

45. Matarese G, Moschos S, Mantzoros CS. Leptin in immunology. J Immunol. 2005;174(6):3137-3142.

46. Krude H, Biebermann H, Luck W, Horn R, Brabant G, Gruters A. Severe early-onset obesity, adrenal insufficiency and red hair pigmentation caused by POMC mutations in humans. Nat Genet. 1998;19(2):155-157.

47. Krude H, et al. Obesity due to proopiomelanocortin deficiency: three new cases and treatment trials with thyroid hormone and ACTH4-10. J Clin Endocrinol Metab. 2003;88(10):4633-4640.

48. Farooqi IS, et al. Heterozygosity for a POMC-null mutation and increased obesity risk in humans. Diabetes. 2006;55(9):2549-2553.

49. Lee YS, et al. A POMC variant implicates beta-melanocyte-stimulating hormone in the control of human energy balance. Cell Metab. 2006;3(2):135-140.

50. Biebermann $\mathrm{H}$, et al. A role for beta-melanocyte- stimulating hormone in human body-weight reguation. Cell Metab. 2006;3(2):141-146.

51. Creemers JW, et al. Mutations in the amino-terminal region of proopiomelanocortin (POMC) in patients with early-onset obesity impair POMC sorting to the regulated secretory pathway. J Clin Endocrinol Metab. 2008;93(11):4494-4499.

52. Jackson RS, et al. Obesity and impaired prohormone processing associated with mutations in the human prohormone convertase 1 gene [see comments]. Nat Genet. 1997;16(3):303-306.

53. Jackson RS, et al. Small-intestinal dysfunction accompanies the complex endocrinopathy of human proprotein convertase 1 deficiency. J Clin Invest. 2003;112(10):1550-1560.

54. Farooqi IS, et al. Hyperphagia and early-onset obesity due to a novel homozygous missense mutation in prohormone convertase 1/3. J Clin Endocrinol Metab. 2007;92(9):3369-3373

55. Faroogi IS, Keogh JM, Yeo GS, Lank EJ, Cheetham T, O'Rahilly S. Clinical spectrum of obesity and mutations in the melanocortin 4 receptor gene. N Engl J Med. 2003;348(12):1085-1095.

56. Alharbi KK, et al. Prevalence and functionality of paucimorphic and private MC4R mutations in a large, unselected European British population, scanned by meltMADGE. Hum Mutat. 2007;28(3):294-302.

57. Farooqi IS, et al. Dominant and recessive inheritance of morbid obesity associated with melanocortin 4 receptor deficiency. J Clin Invest. 2000; 106(2):271-279.

58. Vaisse C, Clement K, Durand E, Hercberg S, GuyGrand B, Froguel P. Melanocortin-4 receptor mutations are a frequent and heterogeneous cause of morbid obesity. J Clin Invest. 2000;106(2):253-262.

59. Stutzmann F, et al. Prevalence of MC4R deficiency in European population and their age-dependant penetrance in multi-generational pedigrees. Diabetes. 2008;57(9):2511-2518

60. Lubrano-Berthelier C, et al. Melanocortin 4 receptor mutations in a large cohort of severely obese adults: prevalence, functional classification, genotype-phenotype relationship, and lack of association with binge eating. J Clin Endocrinol Metab. 2006;91(5):1811-1818.

61. Faroogi IS. The severely obese patient - a genetic work-up. Nat Clin Pract Endocrinol Metab. 2006; 2(3):172-177

62. Rene $\mathrm{P}$, et al. Pharmacological chaperones restore function to MC4R mutants responsible for severe early-onset obesity. J Pharmacol Exp Ther. 2010;335(3):520-532

63. Nogueiras R, et al. The central melanocortin system directly controls peripheral lipid metabolism. J Clin Invest. 2007;117(11):3475-3488.

64. Tallam LS, Stec DE, Willis MA, da Silva AA, Hall JE. Melanocortin-4 receptor-deficient mice are not hypertensive or salt-sensitive despite obesity, hyperinsulinemia, and hyperleptinemia. Hypertension. 2005;46(2):326-332.

65. Greenfield JR, et al. Modulation of blood pressure by central melanocortinergic pathways. $N$ Engl J Med. 2009;360(1):44-52.

66. Greenfield JR. Melanocortin signalling and the regulation of blood pressure in human obesity. J Neuroendocrinol. 2011;23(2):186-193.

67. Martinelli CE, et al. Obesity due to Melanocortin 4 receptor (MC4R) deficiency is associated with increased linear growth and final height, fasting hyperinsulinemia, and incompletely suppressed growth hormone secretion. J Clin Endocrinol Metab. 2011;96(1):E181-E188.

68. Martin NM, et al. Abnormalities of the somatotrophic axis in the obese agouti mouse. Int J Obes (Lond). 2006;30(3):430-438.

69. Xu B, et al. Brain-derived neurotrophic factor regulates energy balance downstream of melanocortin- 
4 receptor. Nat Neurosci. 2003;6(7):736-742.

70. Yeo GS, et al. A de novo mutation affecting human TrkB associated with severe obesity and developmental delay. Nat Neurosci. 2004;7(11):1187-1189.

71. Gray J, et al. Hyperphagia, severe obesity, impaired cognitive function, and hyperactivity associated with functional loss of one copy of the brainderived neurotrophic factor (BDNF) gene. Diabetes. 2006;55(12):3366-3371.

72. Han JC, et al. Brain-derived neurotrophic factor and obesity in the WAGR syndrome. N Engl J Med. 2008;359(9):918-927.

73. Holder JL Jr, Butte NF, Zinn AR. Profound obesity associated with a balanced translocation that disrupts the SIM1 gene. Hum Mol Genet. 2000;9(1):101-108

74. Hung CC, et al. Studies of the SIM1 gene in relation to human obesity and obesity-related traits. Int J Obes (Lond). 2007;31(3):429-434.

75. Michaud JL, et al. Sim1 haploinsufficiency causes hyperphagia, obesity and reduction of the paraventricular nucleus of the hypothalamus. Hum Mol Genet. 2001;10(14):1465-1473.

76. Tolson KP, Gemelli T, Gautron L, Elmquist JK, Zinn AR, Kublaoui BM. Postnatal Sim 1 deficiency causes hyperphagic obesity and reduced $\mathrm{Mc} 4 \mathrm{r}$ and oxytocin expression. J Neurosci. 2010;30(10):3803-3812.

77. Kublaoui BM, Holder JL Jr, Gemelli T, Zinn AR Sim1 haploinsufficiency impairs melanocortinmediated anorexia and activation of paraventricular nucleus neurons. Mol Endocrinol. 2006; 20(10):2483-2492.

78. Kublaoui BM, Gemelli T, Tolson KP, Wang Y, Zinn AR. Oxytocin deficiency mediates hyperphagic obesity of Sim 1 haploinsufficient mice. Mol Endocrinol. 2008;22(7):1723-1734

79. Tobin JL, Beales PL. Bardet-Biedl syndrome: beyond the cilium. Pediatr Nephrol. 2007;22(7):926-936

80. Ansley SJ, et al. Basal body dysfunction is a likely cause of pleiotropic Bardet-Biedl syndrome. Nature. 2003;425(6958):628-633.

81. Ainsworth C. Cilia: tails of the unexpected. Nature. 2007;448(7154):638-641.

82. Seo S, Guo DF, Bugge K, Morgan DA, Rahmoun $\mathrm{K}$, Sheffield VC. Requirement of Bardet-Biedl syndrome proteins for leptin receptor signaling. Hum Mol Genet. 2009;18(7):1323-1331.

83. Davenport JR, et al. Disruption of intraflagel- lar transport in adult mice leads to obesity and slow-onset cystic kidney disease. Curr Biol. 2007; 17(18):1586-1594.

84. Sahoo T, et al. Prader-Willi phenotype caused by paternal deficiency for the HBII-85 C/D box small nucleolar RNA cluster. Nat Genet. 2008; 40(6):719-721.

85. de Smith AJ, et al. A deletion of the HBII-85 class of small nucleolar RNAs (snoRNAs) is associated with hyperphagia, obesity and hypogonadism. Hum Mol Genet. 2009;18(17):3257-3265.

86. Cummings DE, et al. Elevated plasma ghrelin levels in Prader Willi syndrome. Nat Med. 2002;8(7):643-644.

87. Haqq AM, et al. Serum ghrelin levels are inversely correlated with body mass index, age, and insulin concentrations in normal children and are markedly increased in Prader-Willi syndrome. J Clin Endocrinol Metab. 2003;88(1):174-178.

88. Swaab DF, Purba JS, Hofman MA. Alterations in the hypothalamic paraventricular nucleus and its oxytocin neurons (putative satiety cells) in PraderWilli syndrome: a study of five cases. J Clin Endocrinol Metab. 1995;80(2):573-579.

89. Weinstein LS, Chen M, Liu J. Gs(alpha) mutations and imprinting defects in human disease. Ann NY Acad Sci. 2002;968:173-197.

90. Chen $\mathrm{M}$, et al. Central nervous system imprinting of the $\mathrm{G}$ protein $\mathrm{G}(\mathrm{s})$ alpha and its role in metabolic regulation. Cell Metab. 2009;9(6):548-555.

91. Bochukova EG, et al. Large, rare chromosomal deletions associated with severe early-onset obesity. Nature. 2010;463(7281):666-670.

92. Walters RG, et al. A new highly penetrant form of obesity due to deletions on chromosome 16p11.2. Nature. 2010;463(7281):671-675.

93. Ren D, Li M, Duan C, Rui L. Identification of SH2$\mathrm{B}$ as a key regulator of leptin sensitivity, energy balance, and body weight in mice. Cell Metab. 2005; 2(2):95-104.

94. Frayling TM, et al. A common variant in the FTO gene is associated with body mass index and predisposes to childhood and adult obesity. Science. 2007;316(5826):889-894.

95. Dina C, et al. Variation in FTO contributes to childhood obesity and severe adult obesity. Nat Genet. 2007;39(6):724-726.

96. Loos RJ, et al. Common variants near MC4R are associated with fat mass, weight and risk of obesity.
Nat Genet. 2008;40(6):768-775

97. Speliotes EK, et al. Association analyses of 249,796 individuals reveal 18 new loci associated with body mass index. Nat Genet. 2010;42(11):937-948.

98. Wardle J, Carnell S, Haworth CM, Farooqi IS, O'Rahilly S, Plomin R. Obesity-associated genetic variation in FTO is associated with diminished satiety. J Clin Endocrinol Metab. 2008;93(9):3640-3643.

99. Cecil JE, Tavendale R, Watt P, Hetherington MM, Palmer CN. An obesity-associated FTO gene variant and increased energy intake in children. $N E n g l$ JMed. 2008;359(24):2558-2566.

100.Gerken T, et al. The obesity-associated FTO gene encodes a 2-oxoglutarate-dependent nucleic acid demethylase. Science. 2007;318(5855):1469-1472.

101. Stratigopoulos G, et al. Regulation of Fto/Ftm gene expression in mice and humans. Am J Physiol Regul Integr Comp Physiol. 2008;294(4):R1185-R1196.

102. Fischer J, et al. Inactivation of the Fto gene protects from obesity. Nature. 2009;458(7240):894-898

103. Church C, et al. Overexpression of Fto leads to increased food intake and results in obesity. Nat Genet. 2010;42(12):1086-1092.

104. Willer CJ, et al. Six new loci associated with body mass index highlight a neuronal influence on body weight regulation. Nat Genet. 2009;41(1):25-34.

105 . Thorleifsson $G$, et al. Genome-wide association yields new sequence variants at seven loci that associate with measures of obesity. Nat Genet. 2009;41(1):18-24.

106. Ng SB, et al. Targeted capture and massively parallel sequencing of 12 human exomes. Nature. 2009;461(7261):272-276

107. Roach JC, et al. Analysis of genetic inheritance in a family quartet by whole-genome sequencing. $\mathrm{Sci}$ ence. 2010;328(5978):636-639.

108. Price AL, et al. Pooled association tests for rare variants in exon-resequencing studies. Am J Hum Genet. 2010;86(6):832-838.

109. Bulik CM, Allison DB. The genetic epidemiology of thinness. Obes Rev. 2001;2(2):107-115.

110. Ng SB, et al. Exome sequencing identifies the cause of a mendelian disorder. Nat Genet. 2010;42(1):30-35.

111.McCurdy CE, et al. Maternal high-fat diet triggers lipotoxicity in the fetal livers of nonhuman primates. JClin Invest. 2009;119(2):323-335.

112. Feinberg AP, et al. Personalized epigenomic signatures that are stable over time and covary with body mass index. Sci Transl Med. 2010;2(49):49ra67. 